\title{
In Defense of Sandra Stotsky
}

\section{Richard Phelps}

In a review essay appearing in the Fall 2019 issue of AQ, James Shuls criticized author Sandra Stotsky for suggesting in her 2018 book Changing the Course of Failure that the federal government should offer something resembling a boarding school education to the most at-risk students. “That's a dangerous belief," Shuls wrote, “it would be a short step for someone on the fringe to take from Stotsky's idea of a voluntary boarding school to the mandatory internment of low achieving children." In a response to Shuls in the same issue, Stotsky explained that her recommendation was one of several that addressed a fact that educators have failed to adequately address: "massive adolescent underachievement is a social problem, one that has not been solved by our educational institutions in over fifty years.” Below, Richard Phelps offers a defense of Stotsky's body of work followed by a reply from Shuls.

Sandra Stotsky can claim experience that the vast majority of pundits, policy advisors, and advocates who directly influence our country's education policy cannot: she helped design and operate a large-scale program-combining reforms of curriculum, professional development, and student assessmentthat consistently raised educational achievement for all students. She put in the long hours working out the details, reaching consensus, making adjustments, and managing systemwide solutions that worked. Her patient work was integral to the Massachusetts "education miracle” of the 1990s and early 2000s, the envy of forty-nine states. Few individuals involved in education reform in the United States have affected as much positive change.

Stotsky, a co-author with me and Mark McQuillan on a 2015 study for the Pioneer Institute for Public Policy Research, also deserves respect for her independence of thought and word. In a U.S. education policy world full of grifters, enablers, and sellouts, organized largely into cliques, Sandra Stotsky shines

Richard Phelps is founder of the Nonpartisan Education Review (http://www.nonpartisaneducation.org); mail@nonpartisaneducation.org. His most recent books are Defending Standardized Testing (Psychology Press, 2005), Standardized Testing Primer (Peter Lang, 2007), and Correcting Fallacies about Educational and Psychological Testing (American Psychological Association, 2009). 
through. Like so many of the policy analysts aligned with either of the major political parties, she could have taken the money and become a prominent player in the Gates Foundation's regressive Common Core initiative. Unlike so many others, however, she has chosen to keep her own counsel, navigated by a steady compass of core principles and evidence.

Not conforming, however, appears to have made her some enemies. In an astonishingly slanted review of the first of her two recent books (Academic Questions, Fall 2019, 412-421), James V. Shuls accused her of writing what she did not and characterized its entirety based on his misreading of just one of her several suggested "possible long-term solutions."

Briefly, in response to Shuls's perverted perspective, in Changing the Course of Failure:

1. Sandra Stotsky does not advocate centralizing all federal programs. Rather, in several dozen pages, she lays out in detail how the federal government's usurpation of the Tenth Amendment has made a hash of things.

2. Stotsky does not claim that "all the old ideas have faltered," nor does she "throw up her hands” and lament that nothing works. Indeed, she rather prominently showcases the genuine successes of the past, such as: the Massachusetts Education Reform Act of 1993; career-technical programs; some charter school networks (e.g., KIPP, BASIS, Success Academies); teacher licensure in the subject areas; and international benchmarking with curriculum-based tests (such as The Trends in International Mathematics and Science Study and The Progress in International Reading Literacy Study).

3. By floating the suggestion for voluntary, federally-funded boarding schools for those most at risk, Stotsky was hardly offering a radical, extreme suggestion. Similar proposals have been made by others. And indeed, evidence suggests that it works far better than the usual alternatives for the most at-risk children.

In my last full-time job before semi-retirement, I worked as research director for The Association of Boarding Schools, the member association of the 200-plus college-preparatory boarding schools in the United States and Canada (along with several “American schools” overseas). As such, in November 2016 I participated in an international conference in Hanover, Germany. The conference was devoted entirely to boarding school options for at-risk students worldwide. 
Contrary to Shuls's assertion that any such program is just a “short step” to "mandatory internment of low achieving children," these programs, which are government-funded in most countries, have much to recommend them. Many in the U.S. may be aware of the foundation-funded, scholarship-only Milton Hershey School and Girard College in Pennsylvania or Boys Town in Nebraska. My own state of North Carolina hosts the hybrid public-private Crossnore School, which takes in the most troubled children who have nowhere else to go. Graduates I have met told me that their time there saved their lives.

In the years following World War II, the United States hosted several hundred low-cost military schools where troubled or disorganized children might go to learn focus and discipline within a highly structured environment. Most have since closed, victims of anti-military sentiment from the 1960s on, and now number less than a few dozen.

In their place have arisen hundreds of private "therapeutic" boarding schools where some of today's out-of-control or drug-addicted teenagers may find peace in supportive cocoons of licensed counselors, nurses, and social workers. Only some students are welcome, however, because annual fees can exceed one-hundred thousand dollars. Stotsky's proposal could create opportunities for those who might benefit from something similar but cannot now afford therapeutic boarding programs.

Whereas Changing the Course of Failure (2018) focuses on policies for helping low-achieving students, The Roots of Low Achievement (2019), a second book by Stotsky, not considered in Shuls's review, focuses on how our country produces low-achieving students in the first place. If this ordering strikes one as chronologically backwards, an easy solution presents itself-read the second book first. Apparently, Stotsky wrote the two books in the archaeological order of her own investigation into the problem-excavating the upper level of detritus first, then the level underneath, which had been laid down earlier.

The strongest and longest aspect of each book is its historical sweep, and how Stotsky ties it all-the good and the bad-together chronologically, path dependencies and all.

Despite the density of information, each book moves quickly in order to cover a century's worth (in Changing the Course) or a half-century's worth (in Roots) of detail in a little over a hundred pages. Only someone with Stotsky's range of experience and depth of accumulated knowledge could have pulled 
this off. Some common themes appear throughout each. I'll address a few of the more intriguing.

\section{Culture}

Stotsky is brave enough to voice an obvious fact that most education leaders refuse to acknowledge publicly: some students are less motivated than others. If, after years of begging students to be more interested in academics, they still do not choose to be, we cannot make them. That does not mean that they should be abandoned to lives of homelessness. Other, more realistic options should be offered. The most obvious is career-tech programs for "hands on" boys and girls.

Stotsky notes the superlative graduation rates and long waiting lists for entry into career-tech programs. Yet, because of shortsighted government policies these popular programs are perpetually oversubscribed and underfunded. They require specialized instructors and equipment, so career-tech programs can be expensive. But, compared to the alternatives-either a combination of a longer-than-needed high school stay with two to four expensive college years; or dropping out of high school without a diploma-career-tech programs save money and time for both student and taxpayer in the long run.

Another too-seldomly expressed fact: strong, intact families and a parental reverence for educational achievement are not unique to Asian-American or European-American households. But, because they have become stereotyped as such, it is not politically correct to talk about such issues. Unfortunately, ethnicity and poverty are too often equated in policy discussions with home environment and low achievement.

We are hamstrung in solving problems when we are not allowed to discuss either the problem or its solution. This reticence may serve to help liberal do-gooders avoid uncomfortable discussions, but it doesn't help disadvantaged students.

\section{Gap-Closing}

Another truth that few besides Sandra Stotsky are willing to voice publicly: attempts to “close achievement gaps" inevitably lower achievement for all students.

In 2002, the business-sponsored group Mass Insight surveyed students who did not pass the relatively easy high school graduation exam despite the 
availability of an almost unlimited array of free supplemental courses, tutors, and other services. Any student expending a minimal effort to learn eventually earned a diploma. Nonetheless, there remained some students unwilling to take advantage of any of the help available. When Mass Insight tracked them down, they admitted that they simply were not interested enough to show up for any of the free services.

It is naïve public policy to insist that all students complete a college-track academic program when some students clearly prefer something else. The fault is ours in expecting that all children should like, or at least be willing to tolerate, sitting still at a desk for six hours a day for twelve years.

Attempting to close the gap with immovably recalcitrant students anchoring the bottom necessarily means pulling all other students down, typically allocating the most resources for the smallest possible gains, and either ignoring or deliberately holding back the more ambitious students. This is seen nowhere more clearly than in attempts by New York City Mayor Bill de Blasio and his former schools chancellor Richard Carranza to "diversify" high-performing schools with low-performing students. The two have eliminated academic screening for forty percent of the city's middle schools and remain determined to eliminate the Specialized High School Admissions Test for the city's best high schools. The tests are "unfair, unequal, and untenable to continue," said Carranza. ${ }^{1}$

\section{Misplaced Blame}

In Roots of Low Achievement, Stotsky recalls the still valid and oft-replicated findings of the 1966 Coleman Report, the 1965 Moynihan Report, and Laurence Steinberg's 1997 classic, Beyond the Classroom. All found the preponderance of influence on student academic achievement to lie? outside school, including parents' own education level and aspirations for their children's.

Policy solutions are misdirected when they assign all responsibility for students' success or failure to teachers or schools. Neither can control what happens in the first, most formative years of a child's life, nor even in the majority of their time throughout their school years (i.e., after school, at night, on

1 Selim Algar, "De Blasio wants to scrap admissions testing for elite high schools," New York Post, June 2, 2018; Susan Edelman, "NYC parents upset 'luck' trumps merit in middle-school lottery admissions," New York Post, December 26, 2020. 
weekends, or during breaks and vacations). Students never arrive at the schoolhouse door as tabula rasa.

Teacher quality was the one inside-school factor James Coleman found to be significant in his 1960 s study. Stotsky cautions that the term, like so many others in edu-speak, has been contorted to mean whatever it is in education schools' self-interest to mean. She asserts more specifically that teacher quality should be measured (1) in basic verbal skill and (2) subject-matter mastery.

\section{Sputtering Reforms}

With examples from across several decades, Stotsky shows that brief periods of genuine progress can occur when non-educators focus on education. Examples include high school structural reforms led by higher education interests under Harvard's James Conant in the 1960s; the K-12 standards reform led by college professors and parents' groups in California in the late 1990s; and the Massachusetts Education Reform Act of 1993, steadfastly supported by the business community against an onslaught of efforts to dilute it.

\section{Common Core}

The so-called Common Core State Standards-now our federally-required academic standards - represent both the logical outcome of past mistakes and their continuation. Bill Gates decided to go all in with the creators and managers of the earlier "New Standards Project," who had already had their big education reform chance and failed spectacularly. In the 1990s and early 2000s in three states-California, Kentucky, and Maryland-education progressives were allowed ample sway to implement earlier versions of Common Core-like standards and assessments. In each case, parents, teachers, and policymakers tolerated the resulting chaos for a while, trusting each program's promises, but finally pulled the plug when their patience expired.

These prior failures were either not made known to Gates, or they were somehow explained away. It is difficult to imagine that Bill Gates could have been as successful as he was in business with such shoddy vetting of people or proposals. Yet, the "core" Common Core people are the same people most responsible for the earlier failures.

No reasonable person could dispute Massachusetts's success through the same historical period. It is a stark contrast between the two possible education reform paths-New Standards/Common Core and the Massachusetts Education 
Miracle. Yet, two federal administrations-Bush's and Obama's-hundreds of members of the U.S. Congress, from both major parties, and a gaggle of very wealthy foundations chose to mandate a national rollout of the failure and not the success. Moreover, instead of learning from the inevitable poor results and reversing course, like the horse in Animal Farm they just keep pulling harder.

Misinformation and disinformation saturate U.S. education research and policy, and those with money and power seem unable to see clearly through it. Their vetting of people and evidence can be terrible, and terribly consequential. 